\title{
A Proposed Model to Increase Creativity, Collaboration and Accountability in the Online Classroom
}

\author{
Joy Kutaka-Kennedy
}

\begin{abstract}
As technological advances have revolutionized almost every aspect of our daily lives, the field of education has been evolving to optimally address the opportunities and challenges afforded by these new technologies. Like everything else, education has migrated online; however, some problems need to be addressed, such as the high drop rates for online courses, student disengagement, and course quality. Furthermore, developing the 21st century skills of critical thinking, communication, collaboration and creativity requires that we develop a pedagogy that goes beyond traditional lecture and information transfer models of the past. This paper will describe a few of the problems and possible solutions to online learning and 21st century skills through the use of collaboration and creativity. Accountability for collaborative and creative work will also be addressed.
\end{abstract}

Index Terms-Accountability, collaboration, creativity, online pedagogy.

\section{INTRODUCTION}

Trends indicate that online education will continue to expand and proliferate. With the pervasive adoption of new technologies, online education has become a standard fixture with over $86 \%$ of institutions of higher education (IHEs) offering online courses, up from $72 \%$ ten years ago [1]. In 2012 over $62 \%$ provided completely online programs as compared to $34 \%$ in 2002 [2]. Now almost $70 \%$ consider online education critical as strategic to their future success; in 2002 , less than $50 \%$ of institutions of higher education considered it important to their long term strategy. In 2012 $77 \%$ of academic leaders thought online learning outcomes were equal or better than face to face; that figure was $57 \%$ ten years ago.

\section{THE PROBLEM}

\section{A. The Need for $21^{\text {st }}$ Century Skills}

Numerous professional organizations like the National Education Association [NEA] and the National Research Council [3] have documented the need to educate students in the 21st century skills of critical thinking, communication, collaboration, and creativity. To be competitive in the global market and to be engaged, productive citizens, students need to be critical thinkers, skilled communicators who are culturally competent, collaborative partners, and creative contributors [4]. IHEs are at the forefront of preparing

Manuscript received May 10, 2014; revised July 28, 2014.

J. Kutaka-Kennedy is with National University, San Jose, CA 95128 USA (e-mail: jkutakak@nu.edu). teachers who in turn will educate current and future students in these skills. No longer only content experts, teacher-educators now need to model and teach these more nebulous higher order critical thinking skills to prepare the next generation of classroom teachers [5]. Online education must evolve from passive lecture mode into a more engaged, dynamic process to maximize student learning [6].

\section{B. Prevalence of Online Education}

More than one third of all higher education students take at least one online course, and enrollment in online courses exceeds the rate of overall institutional enrollments [1]. However, with the influx of students to the online venue, higher dropout rates of 10-20\% are problematic [7]. Machado da Silva, Meirelles, Filenga, and Filho [8] studied student's perceptions of information quality (course content), and service quality (teacher and peer interactions) to assess their satisfaction in the virtual learning environment. They found that students' use of online learning and satisfaction levels were positively associated with course content (information, assignments, activities, etc.) and course contacts (personal interactions with instructor and peers). Content and contacts explained $89 \%$ of the variance for user satisfaction; one could extrapolate that satisfied students will be more engaged with their learning experience.

\section{Problems with Online Education}

Isolation is often cited as a contributing factor to the higher online drop-out rate of 10 to $20 \%$, as are the students' age, maturity, and online proficiency [9]. Millennials who enter college are accustomed to the instant access to online tools but may not have the persistence to complete their programs, while older students who work full time and want to further their careers might be limited by technological deficiencies and lack of financial aid [10]. Full time technology workers also often spend most of their day staring at computer screens as it is, so continuing this online work into evening schooling is a challenge [11]. Millennials are also more technological/computer savvy, and have an easier time learning how to maneuver the textbooks and course materials, including handy copy/paste, find functions. Information retention and actual learning is thus not as necessary, when $\mathrm{Ctrl}+\mathrm{F}$ is so readily available [11].

Online educators cannot rely on reading materials, power point lectures, and video clips to teach these "soft skills" needed for the $21^{\text {st }}$ century. To implement best practices for online learning, students must be engaged in constructivist activities and higher order thinking [6], [12]. Effective online educators expand their role as content experts by creating assignments and activities requiring active collaboration in virtual learning communities where interaction is seamless 
and expectations explicit [9], [13]. Ferreira and Lacerda dos Santos [14] found that online instruction with high levels of interactions promoted productive collaborations with creation of new knowledge.

Student engagement has been linked to academic achievement, school retention and student resiliency; lack of engagement can lead to isolation and dropping out [15]. Fredericks identified three types of engagement: cognitive engagement which encompasses creativity, synthesis, analysis and reflective thinking; behavioral engagement which involves participation in academic and social activities and emotional engagement which includes positive and negative responses to people and class activities. Engagement plays a crucial role in student learning, retention, persistence, and success. Collaboration and creativity can be natural pathways to enhance meaningful engagement using a constructive approach [5].

\section{Possible Solutions THROUGH COLlABORATION AND CREATIVITY}

The higher order thinking skills for the $21^{\text {st }}$ century (critical thinking, communication, collaboration and creativity) can be presented in the online classroom through appropriate content development by the instructor. Teaching online is much more labor intensive than face-to-face instruction [1], but the benefits of individualization to students' needs, schedules, and learning style can far exceed the time cost to the instructor [16]. Online collaborative dialogue that synthesizes ideas, encourages debate, and explores related themes requires students to combine inductive and deductive reasoning, often leading to greater depths of knowledge, mastery of content, and satisfaction with learning [14]. Even when optimally desired results were not achieved, Richards, Hunley, Weaver, and Landers found that students reported that the collaborative experience produced benefits in learning and practice which would not have occurred if students had worked individually [17].

Merely being assigned to a group with a task does not guarantee that true collaboration will occur. Goulet, Krentz and Christiansen characterized collaboration as a transformative experience transcending consultation, collegiality, and cooperation [18]. Beres and Turcsanyi-Szabo [16] recommended using individual objectives and group objectives for collaborative learning using mindmaps, project-based learning, inquiry-based learning, games, multimedia and sequential or global learning materials. They emphasize the increased responsibility of learners to demonstrate their group contributions given that interactions are recorded. The authors found that online learning can be very effective in addressing students' learning styles, activity preferences, and self and group evaluation methods. Kim and Sonnenwald found that learning style preferences (cooperative, competitive and/or individualized) influenced how students perceived collaborative practices and outcomes [19].

Baguley, Midgley, and Kerby [20] describe some of the linkages between collaboration and creativity with an emphasis on the myth of the sole creative genius, interdisciplinary group processes, and factors such as communication, leadership, dispositions and expertise. They posit that collaboration is inherently creative, and its successful outcomes are predicated by a mix of factors which can be moderated by instructional design. However, before teachers and students can teach or learn in a creative manner, their creativity must first be nurtured. It is unfortunate that by the time most people reach adulthood, they have lost access to their creativity. "Humans are naturally playful, creative beings ... We're doing something to kids in grade school that drums the creativity out of them" [21].

Berrett [21] pointed out that Einstein's success came from his openness to imagination and creativity, not from the sheer force of his brilliant intellect. His innovations came from a creative reworking of known theories, a willingness to fail, and an exploratory mindset. This type of creative approach is what will be needed to address many of the world's most pressing problems such as global warming, health care, and economic inequity. Bunkers [22] described creativity as generated from three sources: first is revelation, the 'aha' that reveals a sudden illumination as a gift; second is birth, implying the invention of something unique; and third is reincarnation, the changing into a new form. All types of creative generation have value.

Einstein famously said that a problem cannot be solved at the same level in which it was created; creative new connections from various disciplines will likely be needed. Creativity is so valued that students are now required to take a course on creativity as part of their undergraduate degree programs at Stanford University, Carnegie Mellon University, University of Kentucky, University of Kansas, and City University of New York, to name a few [21]. Fostering creativity in teaching and learning can take many forms, and its benefits can be monumental and universal from improved health and well-being to a safer, more sustainable planet. Furthermore, a testament to the importance of creativity is evidenced in a survey conducted by IBM. Chief executives in 1,500 companies from 33 industries around the world were asked to rank characteristics including creativity, integrity, management, discipline, rigor, and vision; creativity came in first [21].

Creativity has become a focus of educational mandates around the world, particularly in the developed American, European, Australian and East Asian countries as reflected in their policy documents [23]. The author stated that creativity must not be "ignored or suppressed through schooling" or left to develop by chance. Education must go beyond the 3 Rs of reading, writing and arithmetic and inculcate creativity, one of the $4 \mathrm{Cs}$ of the $21^{\text {st }}$ century skill set. Shaheen advocated for the evolution of teaching which historically focused on knowledge acquisition to teaching which embraces creativity as a foundational life skill needed to navigate an ever changing and growing knowledge base and emerging problems. Furthermore, Csikszentmihalyi, renowned for his work in positive psychology, sees creativity as an aspect of being in the flow [21]. Flow is an extremely satisfying state of mind in which the individual is fully present, intensely focused, intrinsically motivated and highly energized.

Individual creativity has its place in social change, but group creativity arising out of collaborative models is 
becoming the norm for more and more companies and institutions today. It is widely believed that no single individual, group, or profession can possibly address all of the relevant knowledge and skills to resolve increasingly complex, multifaceted problems facing the world today [19]. Paulus and Nijstad [24] conducted an in-depth analysis of the benefits and pitfalls of group creativity which can lead to innovations, defined as the creative ideas that fundamentally change the culture. Constant change drives innovation (creativity with a big $\mathrm{C}$ ) and routine everyday adaptations (little c creativity) according to Paulus and Nijstad who differentiate creativity as useful or influential versus exploratory and experimental.

To some group creativity is an oxymoron given the social pressure to conform and an individual's fear of "being wrong" outweighing the risk of forwarding novel, divergent or even controversial ideas. Groups can become stuck in socially accepted, normative behavior with resistance to new, different, divergent thinking. However, newcomers can bring in fresh perspectives, novel experiences and new frameworks from which to address problems, and the group can socialize the newcomer more quickly through acclimatization to the new group [24].

To others, collaborative groups can generate new ideas, linkages, associations, perspectives. At Google's Innovation Fridays, employees must show up at work but are then free to explore any interest with any member of the organization. Post-It Notes were developed serendipitously through this type of creative free-wheeling exploration. Similarly, many innovations have derived from Starbucks' similar collaborative group experience when they underwent a major corporate renewal. Countless major projects have been successfully achieved through the creative, collaborative group process, such as the Space Shuttle launches, the Manhattan Project, Google Glasses and the iPhone to name a few. Collaborative groups have become a well-defined part of the institutional landscape across many fields and industries, and it is in our best interest to prepare students and teachers at all levels to become proficient in the creative processes available in group settings.

\section{ACCOUnTABILITY}

Equitably grading collaborative group work has always been problematic for a number of reasons. Students who work hard and take pride in their work resent their peers who have a more apathetic attitude and behavior. It's not uncommon that the most motivated students will do the work of the shirkers to maintain their high standards, while the shirkers are grateful to get good grades based on their partner A-student's efforts. In a face to face classroom, instructors often don't have easy ways to hold students individually accountable for a group's output. For online instructors the virtual learning platform can provide rich opportunities for group collaboration with rigorous individual accountability. Specific pedagogical approaches can facilitate student learning while allowing instructors to fairly evaluate each student's contribution to the group effort. The use of clearly defined expectations and detailed rubrics allows motivated students to target their efforts for maximum success; the work of less motivated students is clearly evidenced by time and date stamped online records of their participation and contributions or lack thereof.

Similarly, creative tasks are widely variable, open-ended and ambiguous, with no clear right or wrong approaches or endpoints. Creative work requires risk-taking, experimenting, trying, failing, evaluating, discarding, and making corrections or new connections. To ascertain if these higher order thinking processes actually occur, students can complete reflective analysis for each project. Instructors can assess their learning based upon a pre-established, shared rubric identifying disparate achievement levels for the creative skills being evaluated.

\section{CONCLUSION}

With the proliferation of online learning and the pressing need to educate students for $21^{\text {st }}$ century, it behooves educators to continue to examine the strengths and limitations of online education, the optimal delivery of content and contact, and the development and practice of collaboration, creativity, communication, and critical thinking skills. As noted in [21], "How is our society going to compete in a global economy if we're teaching students how to adapt to yesterday's world or to today's world?...We're going to be left behind in the dust." We must become forward facing in our educational practices online and elsewhere. Future research could productively identify best practices in course design for content and delivery, and the use of collaboration and creativity could be further explored.

\section{REFERENCES}

[1] I. E. Allen and J. Seaman, Grade Change: Tracking Online Education in the United States, Babson Survey Research Group and Quahog Research Group LLC, 2014.

[2] I. E. Allen and J. Seaman, Changing Course: Ten Years of Online Education in the United States, Babson Survey Research Group and Quahog Research Group LLC, 2013.

[3] National Research Council, Education for Life and Work: Developing Transferable Knowledge and Skills in the $21^{\text {st }}$ Century, Washington DC: The National Academies Press, 2012.

[4] National Education Association, An Educator's Guide to the "Four C's": Preparing $21^{\text {st }}$ Century Students for a Global Society, Washington DC: National Education Association, 2012.

[5] D. Kaufman and J. G. Brooks, "Interdisciplinary collaboration in teacher education: A constructivist approach," TESOL Quarterly, vol. 30, no. 2, pp. 231-251, Spring 1996.

[6] E. Mazur, "Farewell, lecture?" Science, vol. 323, no. 2, pp. 50-51, Jan. 2009.

[7] S. Carr, "As distance education comes of age, the challenge is keeping the students," Chronicle of Higher Education, vol. 46, no. 23, p. 39, Feb. 2000 .

[8] F. N. M. D. Silva, F. D. S. Meirelles, D. Filenga, and M. B. Filho, "Student satisfaction process in virtual learning system: Considerations based in information and service quality from Brazil's experience,' Turkish Online Journal of Distance Education, vol. 15, no. 3, p. 11, July 2014.

[9] T. A. Wikle, "Planning considerations for online certificates and degrees in GIS," URISA Journal, vol. 22, no. 2, p. 21, July 2010.

[10] D. DiBiase and K. Kidwai, "Wasted on the young? Comparing the performance and attitudes of younger and older U.S. adults in an online class on geographic information," Journal of Geography in Higher Education, vol. 34, no. 3, pp. 299-326, Aug. 2010.

[11] S. Kennedy, Personal Communication, Avid Technologies, 280 Bernardo Avenue, Mountain View, CA, July 2014.

[12] J. Adams, M. H. Defleur, and G. R. Heald, "The acceptability of credentials earned online for obtaining employment in the health care professions," Communication Education, vol. 56, pp. 292-307, Mar. 2007. 
[13] N. Srichanyachon, "The barriers and needs of online learners," Turkish Online Journal of Distance Education, vol. 15, no. 3, July 2014.

[14] D. J. Ferreira, and G. Lacerda dos Santos, "Productive discussions for online collaborative creativity," Interacções, no. 17, pp. 189-207, 2011.

[15] J. Fredericks, "School engagement: Potential of the concept, state of the evidence," Review of Educational Research, vol. 74, no. 1, pp. 59-109, Jan. 2004.

[16] I. Beres and M. Turcsanyi-Szabo, "Added value model of collaboration in higher education," Interdisciplinary Journal of e-Learning and Learning Objects, vol. 6, pp. 203-215, Annual 2010.

[17] S. B. Richards, S. Hunley, R. Weaver, and M. F. Landers, "A proposed model for teaching collaboration skills to general and special education preservice candidates," Teacher Education and Special Education, vol 26, no. 3, pp. 246-250, Jan. 2003.

[18] L. Goulet, C. Krentz, and H. Christiansen, "Collaboration in education: The phenomenon and process of working together," Alberta Journal of Educational Research, vol. 49, no. 4, pp. 325-340, Winter 2003.

[19] S.-L. Kim and D. H. Sonnenwald, "Investigating the relationship between learning style preferences and teaching collaboration skills and technology: An exploratory study," in Proc. the American Society for Information Science and Technology, vol. 39, no. 1, pp. 64-73, Nov. 2002.

[20] M. Baguley, W. Midgley, and M. Kerby, "Epilogue: Creativity and collaboration in the education sector," International Journal of Pedagogies and Learning, vol. 8, no. 1, pp. 53-54, Apr. 2013.

[21] D. Berrett, "Creativity: A cure for the common curriculum," Chronicle of Higher Education, vol. 59, no. 30, pp. 33-36, Apr. 2013.

[22] S. S. Bunkers, "Fostering the creative spirit in teaching-learning," Nursing Science Quarterly, vol. 22, no. 4, pp. 323-325, Oct. 2009.

[23] R. Shaheen, "Creativity and education," Creative Education, vol. 1, no. 3, pp. 166-169, Dec. 2009.

[24] P. B. Paulus and B. A. Nijstad, Group Creativity: Innovation through Collaboration, Cary, NC: Oxford University Press, Inc, 2003, ch. 1, pp. $2-21$.

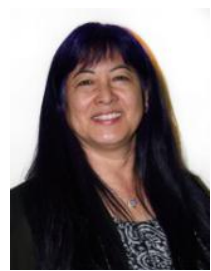

Joy Kutaka-Kennedy is a member of IACSIT. She was born in Wailuku, Hawaii. She obtained her bachelors of science in psychology from Stanford University in 1974, her masters of science in education with an emphasis on curriculum from California State University Hayward in 1993, and her doctorate in learning and instruction with a specialization in special education from the University of San Francisco in 2003. Her major field is special education with emphasis in mild to moderate and moderate to severe disabilities.

She began her teaching career as a $2^{\text {nd }}$ Grade Teacher in 1987, moving forward to teach in grades 5, 6,7 and 8, in the general education classroom of self-contained multiple subjects and in single subject classrooms for reading, language arts, world history, biology and physics. Currently she teaches in special education teacher preparation at National University, San Jose campus and online. She authored Inclusion in General Education Classes: What Do Secondary Students with Emotional and Behavioral Disorders Think? published in Berlin, Germany by VDM Verlag Dr. Müller Aktiengesellschaft \& Co. KG, 2009 and wrote the chapter "Collaboration with Paraprofessionals" in J. M. Madigan and G. Scroth-Cavataio, (Eds.), Mentorship of Special Educators published in Thousand Oaks, CA by Corwin Press 2011. Her current research interests include online education, creativity and colloboration.

Dr. Kutaka-Kennedy has conducted numerous program assessments for undergraduate programs at National University. She serves as the treasurer of California Association of Professors of Special Education and is a member of the American Educational Research Association (AERA). She is an editorial reviewer for the Teacher Education and Special Education Journal and a conference proposal reviewer for AERA and EduLearn. She served a gran proposal reviewer for the United States Department of Education, Office of Special Education Programs. 